\title{
Inspection and Numerical Analysis of an Ottoman Railway Bridge in Jordan
}

\author{
Amin H. Almasri ${ }^{1}$ and Qusai Fandi Al-Waked ${ }^{2}$ \\ ${ }^{1}$ Department of Civil Engineering, Jordan University of Science and Technology, P.O. Box 3030, Irbid 22110, Jordan \\ ${ }^{2}$ Structural Engineering, Coventry University, Priory Street, Coventry CV1 5FB, UK \\ Correspondence should be addressed to Amin H. Almasri; ahalmasri@just.edu.jo
}

Received 24 January 2016; Revised 8 April 2016; Accepted 13 April 2016

Academic Editor: Carlo Santulli

Copyright (C) 2016 A. H. Almasri and Q. F. Al-Waked. This is an open access article distributed under the Creative Commons Attribution License, which permits unrestricted use, distribution, and reproduction in any medium, provided the original work is properly cited.

\begin{abstract}
The construction of bridges represents a big challenge, since they require enormous economic effort and specialized technical skills. Bridges were historically important as they help connecting people and thus diffusing cultures, sharing ideas, and providing the backbone of transportation networks. This study focuses on the inspection and structural analysis of a 20th-century Ottoman railway stone arched bridge located on the Hejaz railway network in Jordan. The bridge has a very important cultural heritage value which stems from its history. The bridge stone material was cut and tested to determine its strength, in order to be used in the analysis. The structural analysis was carried out to assess the structural condition of the bridge and its suitability for reuse. The study includes static analysis under gravity loads and seismic analysis under earthquake loads. Despite the existence of deterioration in the bridge body construction materials due to a combination of human and natural factors, the analysis results proved enough structural capability to sustain the imposed gravity loads, but not a strong earthquake.
\end{abstract}

\section{Introduction}

The Ottoman Empire ruled Jordan for more than 500 years, where an extremely unique heritage has been left behind. Most of the remained tangible heritage is still standing and telling the history of the area. One of the main components of this heritage is the masonry and stone structures that are scattered all over the country. Some of these are the castles along the Hejaz railway [1], the Ottoman village at Umm Qais, the residential buildings, and the railway bridges along the Hejaz railway. These bridges represent the engineering innovation coupled with local participation during the Ottoman period as well as the structural adaptation to the surrounding environment. In other words, the construction of these bridges was meant to utilize the available materials of construction, topography, and the least cost [1].

The bridges on Marka Railway Station and Al-Zarqa'a Railway Station as well as other Ottoman railway bridges in Jordan have not been in use for about a century. This does not actually negate the need for a proper conservation and maintenance of these significant and historical relics. Conservation of these structures includes detailed documentation and complete understanding of the structural behavior of these bridges; the outcome then would be introducing and preserving these heritage bridges to the future generations taking into consideration that these bridges are and will remain part of the Jordanian legacy and contribution to the world cultural heritage. Accordingly, this study focuses on the structural analysis of an Ottoman bridge in Marka, AlZarqa'a Railway. This bridge will serve as a model for future conservation plans of similar bridges in the country.

The literature contains many studies that dealt with historical bridges. To mention few, researchers studied the structural behavior of a historical masonry bridge in Cesena, Italy [2], while others presented a historic inventory of masonry arch bridges in Virginia [3], in addition to other related studies $[4,5]$. Methods of load capacity assessment of stone arch bridges in Sweden using inspections and calculations 
were investigated [6]. Other researchers [7] presented a study about partial collapse and rehabilitation work of a masonry arch bridge in Portugal. Many railway bridges constructed in the last century are still in service worldwide today after having been repeatedly strengthened to meet new needs. Regular assessment is an important part of the management of their further service [8]. Rehabilitation and conservation of ancient bridges have shown in recent years the need of reliable methods for assessment: it is important not only to maintain ancient structures in good conditions, but also, when necessary, to be able to estimate their safety factor as accurately as possible [9]. Banić et al. [10] presented analysis and reconstruction projects of three small stone arch bridges. Their goal was to meet the bearing capacity, durability requirements, and conservators' requirements in terms of conservation of bridge's original identity. Bayraktar et al. [11] determined the frequency and damping ratios of eight historical masonry arch bridges experimentally. Operational Modal Analysis Method is used to obtain the experimental dynamic characteristics of the bridges. A full historical review about arch bridges including masonry bridges was done by Beyer [12].

However, no previous studies regarding structural analysis have been conducted on bridges found in Jordan. This indicates that these bridges have been neglected despite the fact that they represent a valuable heritage in terms of their construction, engineering innovation, and historical value. Moreover, besides being of high historical significant reliable bridges, Ottoman railway bridges are an essential and integral component of a safe transportation system. In addition to that, future plans of the Jordanian government regarding the Hejaz railway between Amman and Al-Zarqa stress on the issue of reactivating the railway network to their new utilitarian function and rehabilitation, which will require a proper understanding of the structural behavior of the various Ottoman bridges, and this is yet to be achieved.

Nowadays existing masonry arch bridges are very important to be studied since they represent a very significant part of national roads and rails network, both in terms of numerical quantity and for the quality of their structural response and their environmental integration. In fact it is always masonry arch bridges which survived until today and continue to be in use without any clear change to their original shape. This is possible due to the high self-weight together with masonry mechanical characteristics that allow these bridges to have a high relevant strength and stiffness compared with the loads they are carrying. Maybe this is one of the most important aspects of the masonry arch bridges which permits these ancient structures to stay in good health at the present time. However it cannot be forgotten that weight and traffic are increasing during the last 100 years and these new elements will eventually lead to the deterioration of the bridges fabric.

To take measures towards preserving and rehabilitating of such bridges, enough information is needed about all conditions of the bridge. In this case, finite element analysis can be of great help to provide information about stresses and strains in bridge body.

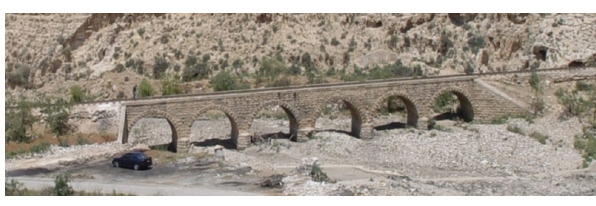

Figure 1: General view of the bridge.

\section{Background and Visual Investigation}

The case study bridge is the Marka-Al-Zarqa Railway Ottoman Bridge in the middle of Jordan, which is a multispan arch bridge with backfill as shown in Figure 1. The bridge is supported by six semicircular masonry stone arches equally spanned at $6 \mathrm{~m}$, as shown in Figure 2. The bridge reaches a total length of $44.29 \mathrm{~m}$ and has a roadway width of $3.95 \mathrm{~m}$ with a parapet on each side. The bridge is supported by five stone piers, two abutments, and four wing walls. The piers on the water upstream side terminate in prominent triangular breakwaters along with the direction of the stream and on the downstream side in polygonal buttresses ending in pyramidal shape as shown in Figure 3. The arch system used in the bridge consists of a keystone of $0.55 \mathrm{~m}$ height on the top middle of the arch and a voussoir with 12 stone pieces to the springer on each side of the arch. The rise of the arch is $2.48 \mathrm{~m}$, and the arch continues in barrel vault shape into the other side of the bridge. Ottoman builders built a weep holes above each pier as a drainage system for the rain water which falls on the surface of the bridge deck, which are clear in Figure 3.

The arch is one of the oldest forms of bridges. It is rather like an inverted suspension bridge, with all the tensions replaced by compressions. The arch is a form of construction in which masonry units span an opening by transferring vertical loads laterally to adjacent voussoirs and, thus, to the abutments [13]. One reason for the stability of many arches is that the volume between road and arch is filled in with masonry, which adds rigidity. In fact the masonry spreads a point load in such a way that its effect reaches several voussoirs of the arch. Masonry arches being made of relatively big voussoirs joined by mortar cannot take tension and need continuous support during construction from below.

The foundations of the arch bridge are relatively shallow spread footings. Stone piers are often solid without any internal cavity. Spandrel and wing walls retain the fill and carry the parapets. The spandrel walls also stiffen the arch ring at its edges and may have a considerable strengthening effect on the vault as a whole. They are commonly thickened towards their base to increase their stability and for the same reason the wing walls are buttressed and built with a sloping outer face. Wing walls can add to the strength of a bridge by restraining the in-plane displacement of the spandrels and were built curved on plan so that the bridge was at its narrowest at midspan, which may make some contribution to their ability to resist the outward pressures from the fill.

The bridge was built using three components: stones, mortar, and the fill. This can be easily seen in another collapsed Ottoman bridge located in Al-Zarqa'a city and was built for the same railway during the same period of 


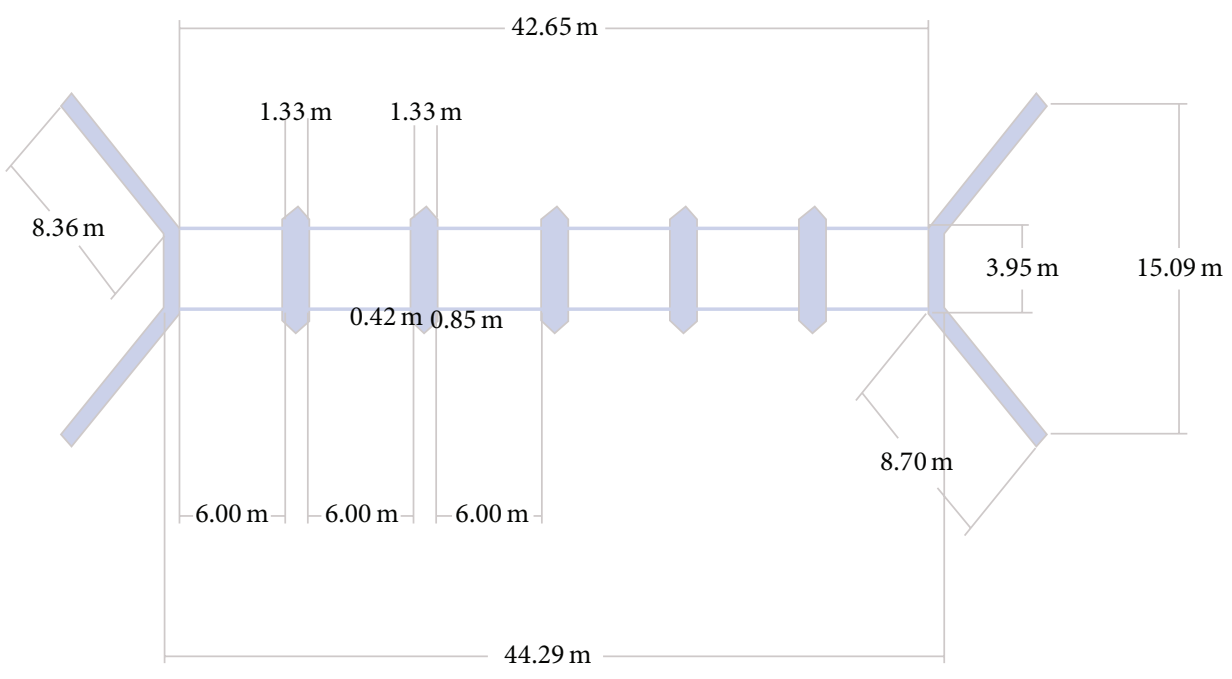

FIgURE 2: Top plan view of the bridge with the dimensions.

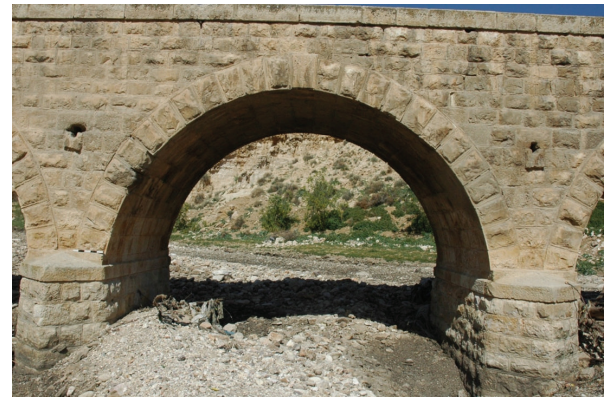

FIgURE 3: Elevation view of an arch and piers.

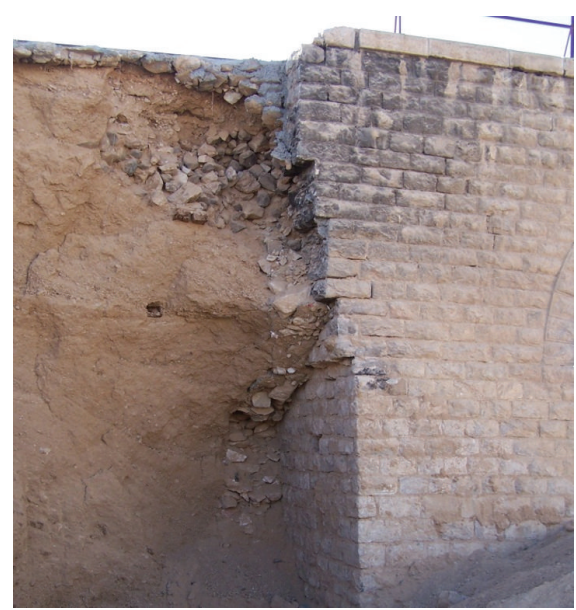

FIgURE 4: Abutment failure that shows the fill materials.

construction. This Ottoman bridge is in very poor structural condition and is facing many structural problems including a failure at one of the bridge abutments, where one can observe easily the bridge fill material (Figure 4). The fill materials of the bridge were consisting of two stone debrises types, with some mortar and broken stones in the middle. All fill often consisted of materials excavated during the building of the foundations. It may nevertheless have high strength as a result of its composition and compaction over the years.

Analyzing, modeling, and evaluation of old arch bridges are difficult tasks. Some of the important reasons behind this are missing detailed geometric data to define the exact structural configuration, the high variability in the material properties due to the selection of natural materials in construction, and nonuniform quality of workmanship for the entire structure. Thus a well understanding of the structural behavior of such bridges, a good engineering judgment with sufficient experience of the old construction techniques and concepts, and correct interpretation of the analysis results of comprehensive structural response are necessary for proper simulation of these bridges.

\section{Methodology}

Visual inspection of the bridge along with digital photography was carried out to collect actual information about the bridge. In addition, dimensions are measured, and samples of bridge stones and mortar were taken for testing. Laboratory material testing of these samples was carried out to obtain compressive strength of bridge stones and mortar. Then finite element analysis of the bridge is performed under different load cases (static and seismic) to evaluate its capacity to withstand such loads without stresses exceeding failure stresses.

One method for analysis of masonry structures is Limit State Analysis. This method is good for predicting stability problems and collapse mechanisms. To apply limit analysis to masonry, three main assumptions can be made: masonry has no tensile strength; it can resist infinite compression; and no sliding will occur within the masonry. However, this method cannot predict stresses or simulate earthquakes and hence was not appropriate for the study goals. Another choice for analysis was Discrete Element Method, which is a numerical method for computing the motion and effect of a large 

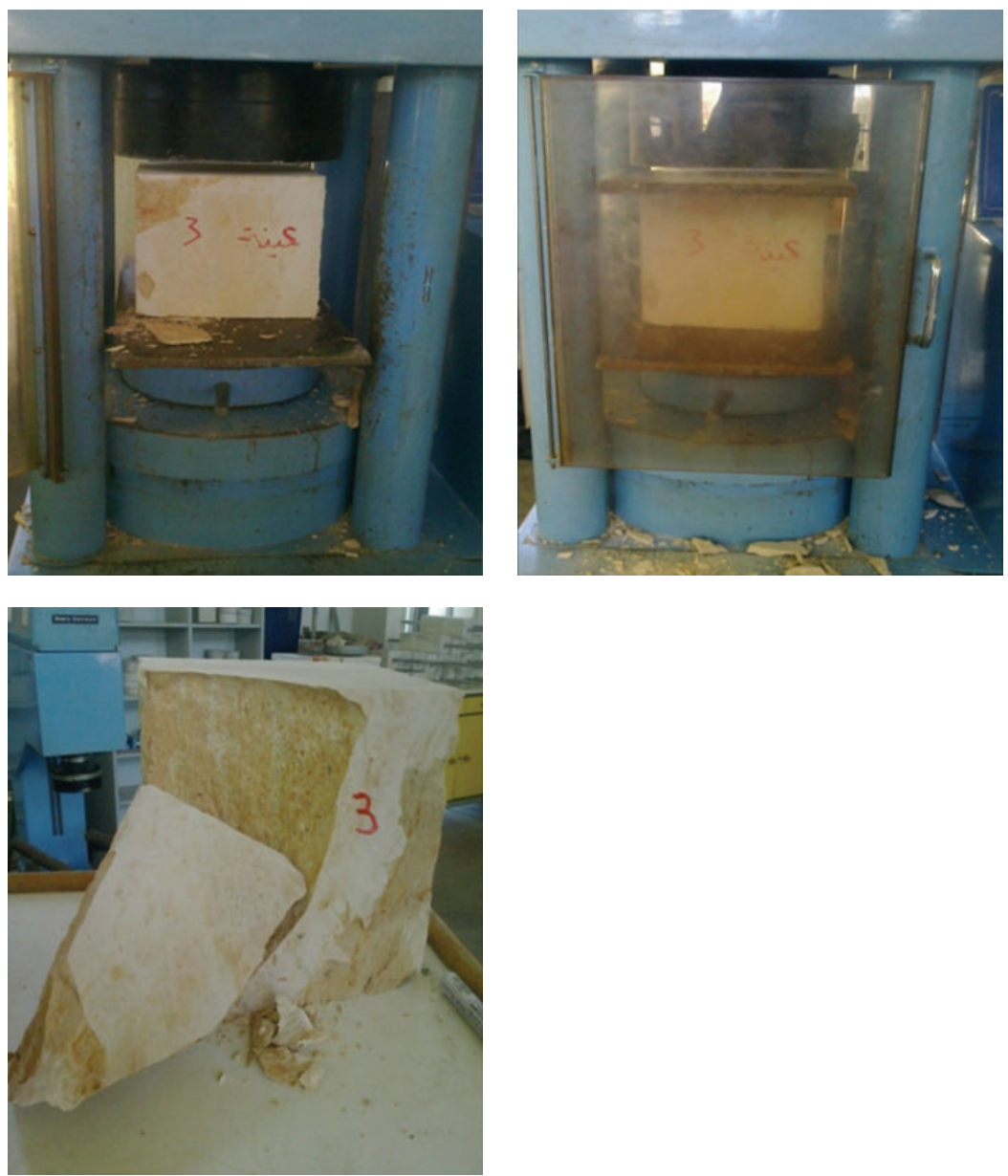

FIGURE 5: Stone sample 3 under compressive strength testing.

number of small particles, which can be good for studying the bridge behavior after stones lose contact between each other, but not before that. Therefore, finite element method seemed to be the best option for stresses analysis especially under earthquake simulation.

\section{Material Testing}

Fortunately, the remains of construction stones were found at the site and were taken for experimental testing. Collected samples were of different sizes and shapes. The samples of a stones were first cut in cubes of size $20 \mathrm{~cm} \times 20 \mathrm{~cm} \times 20 \mathrm{~cm}$. The sides of the cube were then finely dressed and finished. Three specimens were placed in water for 72 hours prior to the test to reach saturation condition and then tested for uniaxial compression strength in Jordan University of Science and Technology laboratories (typical sample is shown in Figure 5). The results of the three samples are shown in Table 1 . Based on test results, the bridge stone compressive strength will be taken as $32 \mathrm{MPa}$.

The strength of the mortar is more difficult to test than that of the stones. Several problems were faced: the deviation of the mortar characteristics, the geometry, and degree of fill of the mortar joints. Moreover, it is hard to obtain suitable
TABLE 1: Compression test results.

\begin{tabular}{lccc}
\hline $\begin{array}{l}\text { Sample } \\
\text { number }\end{array}$ & $\begin{array}{c}\text { Cube dimension } \\
(\mathrm{mm})\end{array}$ & $\begin{array}{c}\text { Ultimate load } \\
(\mathrm{KN})\end{array}$ & $\begin{array}{c}\text { Compressive } \\
\text { strength }(\mathrm{MPa})\end{array}$ \\
\hline 1 & 200 & 1501 & 37.53 \\
2 & 200 & 1102 & 27.55 \\
3 & 200 & 1219 & 30.48 \\
Average & - & - & 31.8 \\
\hline
\end{tabular}

testing pieces from the existing mortar to be tested under compressive strength test. Therefore, in order to be on the safe side, compressive strength of Ottoman lime mortar from previous study [14] was taken as a maximum value for this study, which is $3 \mathrm{MPa}$, and tensile strength to be $10 \%$ of compressive strength, which will be $0.3 \mathrm{MPa}$. So mortar can be considered the weak part of the bridge ingredients.

\section{Finite Element Analysis}

The arch is a compressive structure and its integrity is compromised when tensile stresses occur. A computer structural analysis program, ABAQUS, was used to analyze the bridge 


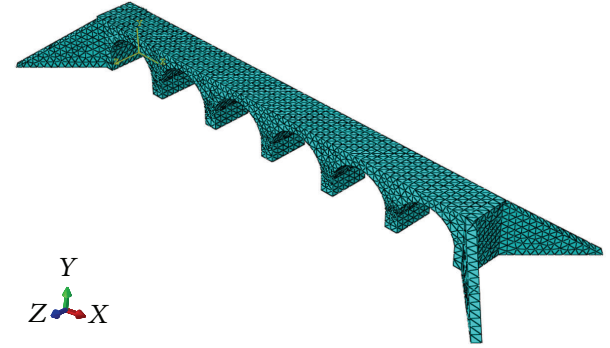

Figure 6: The finite element model.

structure under static and dynamic loading to investigate if tensile stresses would develop. The bridge was simulated using 3D 20 node brick finite element, with three degrees of freedom at each node, namely, the translations along the nodal $x, y$, and $z$ directions. The average dimension of mesh elements size was $0.65 \mathrm{~m}$.

The bridge model was constructed and automatically meshed. The finite element mesh model (Figure 6) had a total number of 28,388 elements and 11,068 nodes. Bridge supports are considered to be fixed at the bottom and at the ends of wing walls.

The average dead load (own weight) of the bridge was calculated in the program through the volume and density of the bridge parts. This parameter is used in order to assess the load carrying capacity of the bridge in terms of the ratio of the external load applied to the self-weight. The live loads were assumed to be $950 \mathrm{kN}$ per 19 meters after taking into consideration a list of locomotives now used by Jordanian Hejaz railway network [15].

In addition to the static analysis, seismic analysis of the bridge was carried out. Three-directional acceleration record of Koyna earthquake $[16,17]$ was utilized in time history analysis in order to assess the bridge seismic structural capacity. It is worth pointing out that Koyna earthquake was measured to have about 6.3 degrees magnitude on Richter scale. The strongest documented earthquake in Jordan was 6.3 degrees in magnitude at $\mathrm{Al} \mathrm{Karāmah,} \mathrm{Balqa,} \mathrm{Jordan,} \mathrm{which}$ is around $100 \mathrm{~km}$ from the bridge site. That was 89 years ago, in 1927. However, there is no full record for that earthquake, and the strongest fully recorded earthquake in Jordan is of 5.3 degrees in magnitude at more than $400 \mathrm{~km}$ away from the bridge site. Therefore, the authors thought that the wellknown Koyna earthquake record can be used in the present study instead for more reliable results. The record of the earthquake is shown in Figure 7.

The bridge was modeled on the macrolevel, since it will be very costly to include any modeling on the microscale under seismic loading for a structure with this size. Modeling on microscale will not only increases modeling time hugely (based on the authors experience with microscale modeling) but also add many more unnecessary complications to the analysis.

Material mechanical properties were determined experimentally for the stones and are used and compared with the finite element results to see when stones could crush (in compression) or mortar could crack (under tensile stresses) during a strong earthquake. The stone properties (density and modulus of elasticity) were actually used in the analysis since it is the main component of the bridge, and full bond is assumed between stones to simulate mortar. Maximum tensile stresses that develop in the bridge will be compared to mortar tensile strength to see if it will have any tensile cracks or not. Linear analysis was used in modeling the bridge material. Nonlinear material model is not needed here because rocks and mortar can be considered as brittle materials and shows very little or even no material nonlinearity. Hence, it is believed that there is no need for using nonlinear material model with results still accurate enough.

\section{Results and Discussion}

The finite element models have been carried out to determine the locations of the maximum stresses, displacements, and deflections. Figure 8 shows the maximum principal stresses in the bridge under gravity loads (dead and live). It can be seen that the maximum stresses value in the bridge is $0.43 \mathrm{MPa}$, which is mainly due to compressive stresses at the lower parts of the piers. This value is lower than mortar compressive strength with safety factor about 7 .

On the other hand, shear stresses results (Figure 9) show that the maximum shear stress under gravity loads is about $0.0448 \mathrm{MPa}$ and it occurs at the mid of the arch vault. Consequently, all of these results are lower than the bridge building materials strength, which indicates the possibility of reusing the bridge under the current vehicles loads used by Jordanian Hejaz railway network.

According to the finite element analysis, the maximum horizontal displacements are shown in Figure 10 to happen at the two ends of the bridge, where the gravity loads try to bend the abutments. The maximum recorded value was approximately $0.02 \mathrm{~mm}$, which is negligible compared to bridge dimensions. On the other hand, vertical deflection (Figure 11) was recorded to reach about $0.07 \mathrm{~mm}$, which is still small compared to bridge dimensions. This maximum value occurs at the midspans of the arches.

Figures 12 and 13 show minimum principal stresses (tensile stresses) in the bridge due to Koyna earthquake record in $X-Y$ and $Y-Z$ directions, respectively. The seismic analysis results have reported that the maximum stresses were with $Y-Z$ direction (which is the weak direction of the bridge), where the stresses reached about 1.7 MPa. Even in the longitudinal direction of the bridge, the stress reached about 1.1 MPa, which exceeds the tensile strength of the mortar. This could easily lead to serious damage to the bridge mortar and hence to the bridge structural integrity. These stresses happen at the bottom of the piers (at the supports), which indicates that the base shear that initiates from the earthquake is the major factor in these stresses. Slippage may occur between bridge stones due to these stresses which could lead to total collapse of the bridge. This will require different kind of analysis, that is, contact analysis, which is beyond the scope of this paper. 


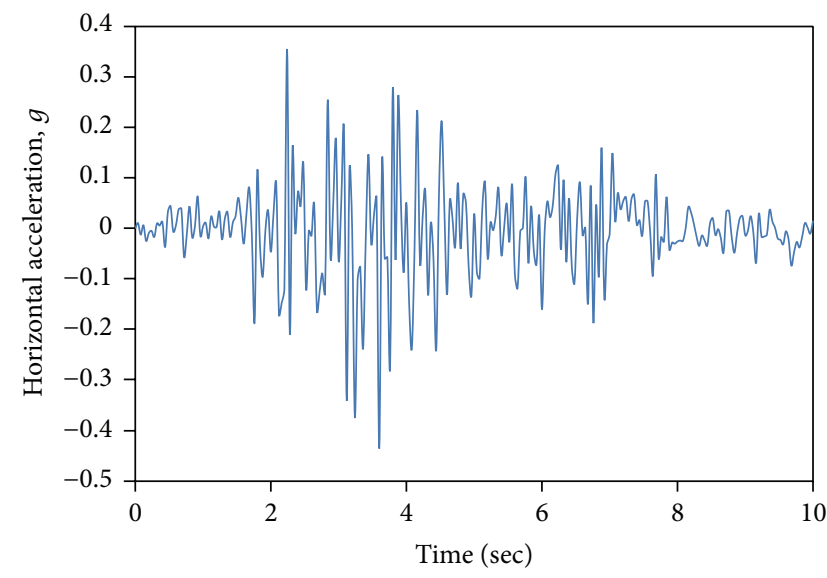

(a)

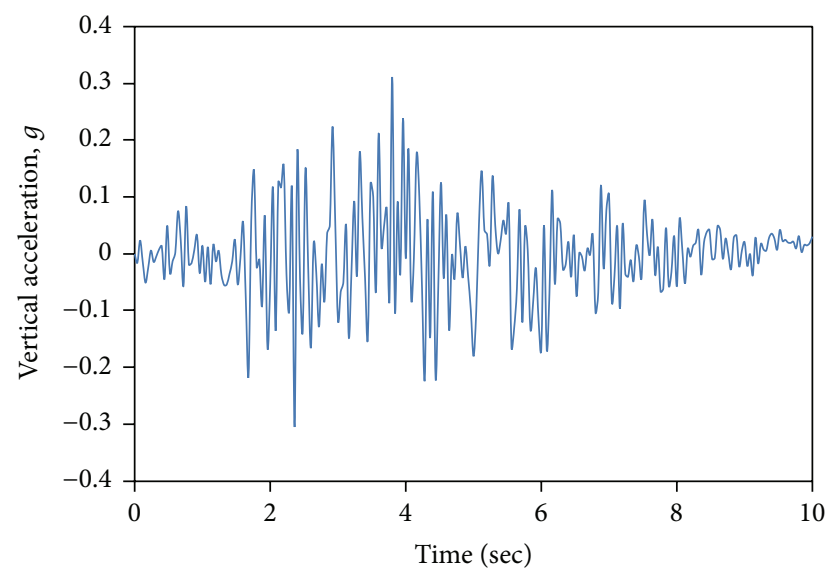

(b)

FIGURE 7: (a) Horizontal and (b) vertical ground acceleration record of Koyna earthquake.

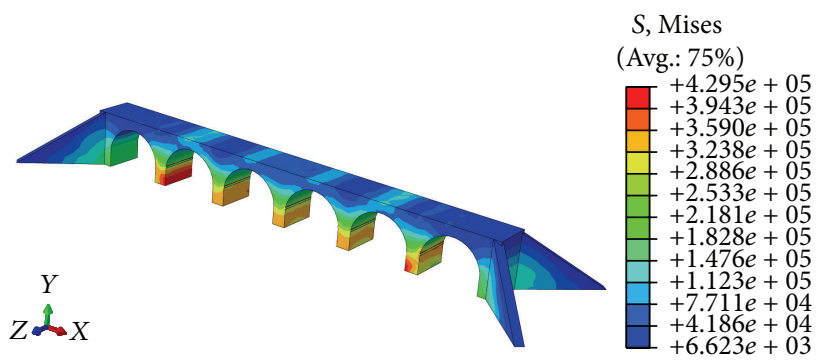

Figure 8: Von-Mises stress in the bridge under gravity loads.

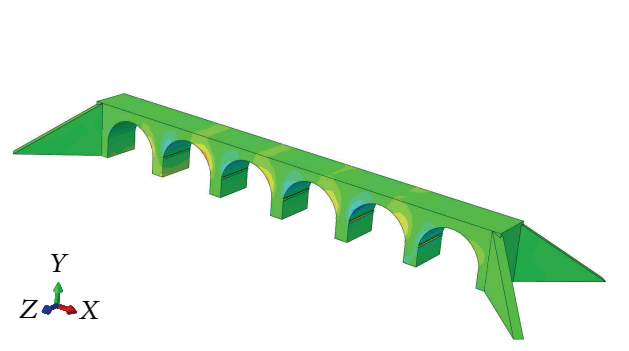

$$
S, S_{12}
$$$$
\text { (Avg.: } 75 \%)
$$

FIGURE 9: Shear stress in the bridge under gravity loads.

\section{Conclusions}

A case study of an Ottoman bridge was analyzed using a finite element method, including static and dynamic earthquake forces, in order to investigate the behavior of the bridge structure. The static and seismic analyses show that the structural configuration of the bridge is adequate to withstand vertical gravity loads but might suffer damages under strong dynamic earthquake loading. The results showed that the maximum values of stresses and displacements are at the midspan of the main arches under gravity loads. Consequently, these locations should be taken care of in the future strengthening studies. On the other hand, the bottom parts of the piers should be strengthened to resist earthquake loadings. Finite

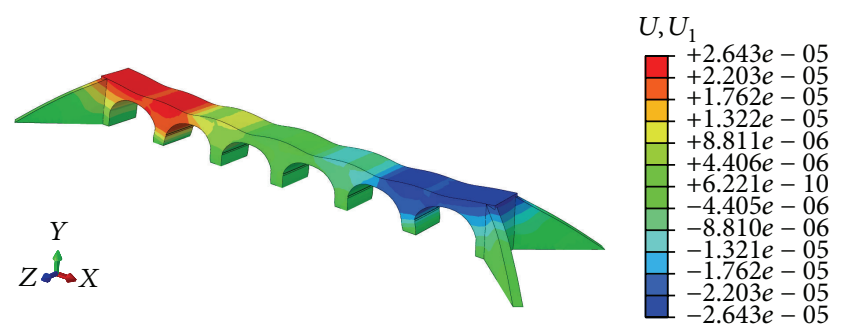

FIGURE 10: Horizontal displacements under gravity loads.
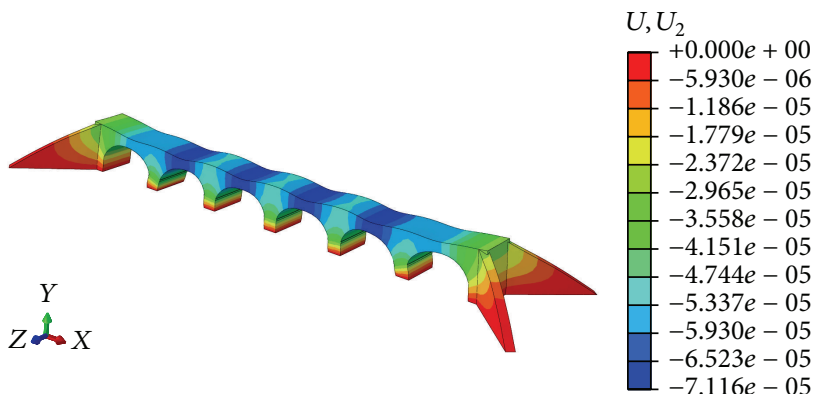

FIGURE 11: Vertical deflection in the bridge due to gravity loads.

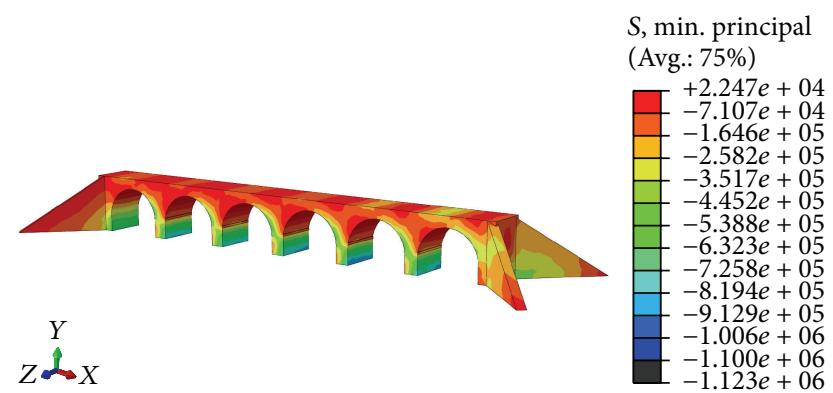

FIgURE 12: Minimum principal stress in the bridge due to earthquake load in $X-Y$ direction. 


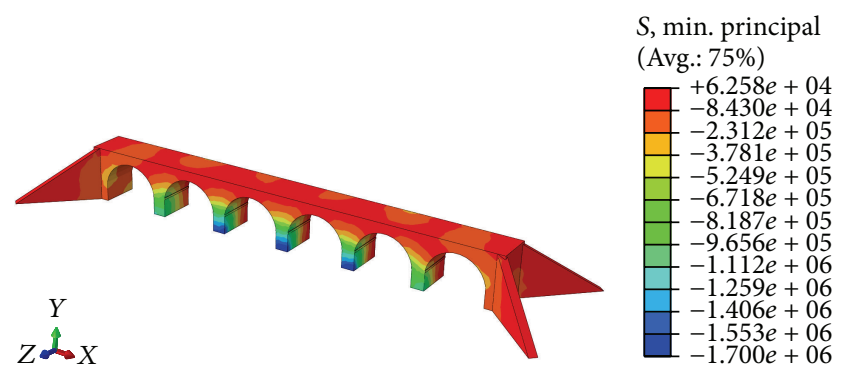

FIgURE 13: Minimum principal stress in the bridge due to earthquake load in $Y-Z$ direction.

element analysis proved to be a very efficient tool in diagnosing current monuments for future preservation plans and actions.

\section{Competing Interests}

The authors declare that they have no competing interests.

\section{References}

[1] W. Ochsenwald, The Hejaz Railway, University Press of Virginia, Charlottesville, Va, USA, 1980.

[2] L. Nobile, V. Bartolomeo, and M. Bonagura, "Structural analysis of historic masonry arch bridges: case study of clemente bridge on Savio River," in Key Engineering Materials, Z. Tonković and M. H. Aliabadi, Eds., vol. 488-489, pp. 674-677, 2011.

[3] A. B. Miller and K. M. Clark, A Survey of Masonry and Concrete Arch Bridges in Virginia, Department of Transportation. USA, Charlottesville, Va, USA, 2000.

[4] A. Ura, S. Oruc, A. Dogangun, and O. Tuluk, "Turkish historical arch bridges and their deteriorations and failures," Engineering Failure Analysis, vol. 15, no. 1-2, pp. 43-53, 2007.

[5] D. Proske and P. V. Gelder, Safety of Historical Stone Arch Bridges, Springer, London, UK, 2009.

[6] H. Kristoffer, On engineering methods for assessment of load capacity of stone arch bridges [M.S. thesis], Chalmers University of Technology, Göteborg, Sweden, 2010.

[7] D. V. Oliveira, V. M. Costa, and J. F. Sousa, "Diagnosis and repair of a historic stone masonry arch bridge," in Proceedings of the 6th International Conference on Arch Bridges (ARCH '10), pp. 817-822, Fuzhou, China, 2010.

[8] P. Kunz and M. A. Hirt, "Reliability of railroad bridges under fatigue loading," in Proceedings of the 3rd International Workshop on Bridge Rehabilitation, pp. 515-528, Darmstadt, Germany, 1992.

[9] G. Frunzio, M. Monaco, and A. Gesualdo, “3D F.E.M. analysis of a Roman arch bridge," in Historical Constructions, P. R. Lourenço, Ed., pp. 591-597, 2001.

[10] D. Banić, D. Novak, and T. Brozović, "Reconstruction of small stone arch bridges in dalmatian hinterland," 2011, https://www .researchgate.net/publication/259609998.

[11] A. Bayraktar, T. Türker, and A. C. Altunişik, "Experimental frequencies and damping ratios for historical masonry arch bridges," Construction and Building Materials, vol. 75, pp. 234241, 2015.
[12] L. Beyer, Arched Bridges, paper 33 [Honors thesis], University of New Hampshire, Durham, NH, USA, 2012.

[13] T. Beuerman, Inventory of repairing and strengthening techniques in masonry arch bridges [M.S. thesis], Polytechnic University of Catalonia, Barcelona, Spain, 2009.

[14] H. Böke, Ö. Çizer, B. Ipekoglu, E. Ugurlu, K. Serifaki, and G. Toprak, "Characteristics of lime produced from limestone containing diatoms," Construction and Building Materials, vol. 22, no. 5, pp. 866-874, 2008.

[15] JHRS, "Locomotives and mechanics," Jordanian Hejaz Railway Station, 2010, http://www.jh-railway.com.

[16] H. K. Gupta, "A review of recent studies of triggered earthquakes by artificial water reservoirs with special emphasis on earthquakes in Koyna, India," Earth-Science Reviews, vol. 58, no. 3-4, pp. 279-310, 2002.

[17] H. Narain and H. Gupta, "Koyna Earthquake," Nature, vol. 217, no. 5134, pp. $1138-1139,1968$. 

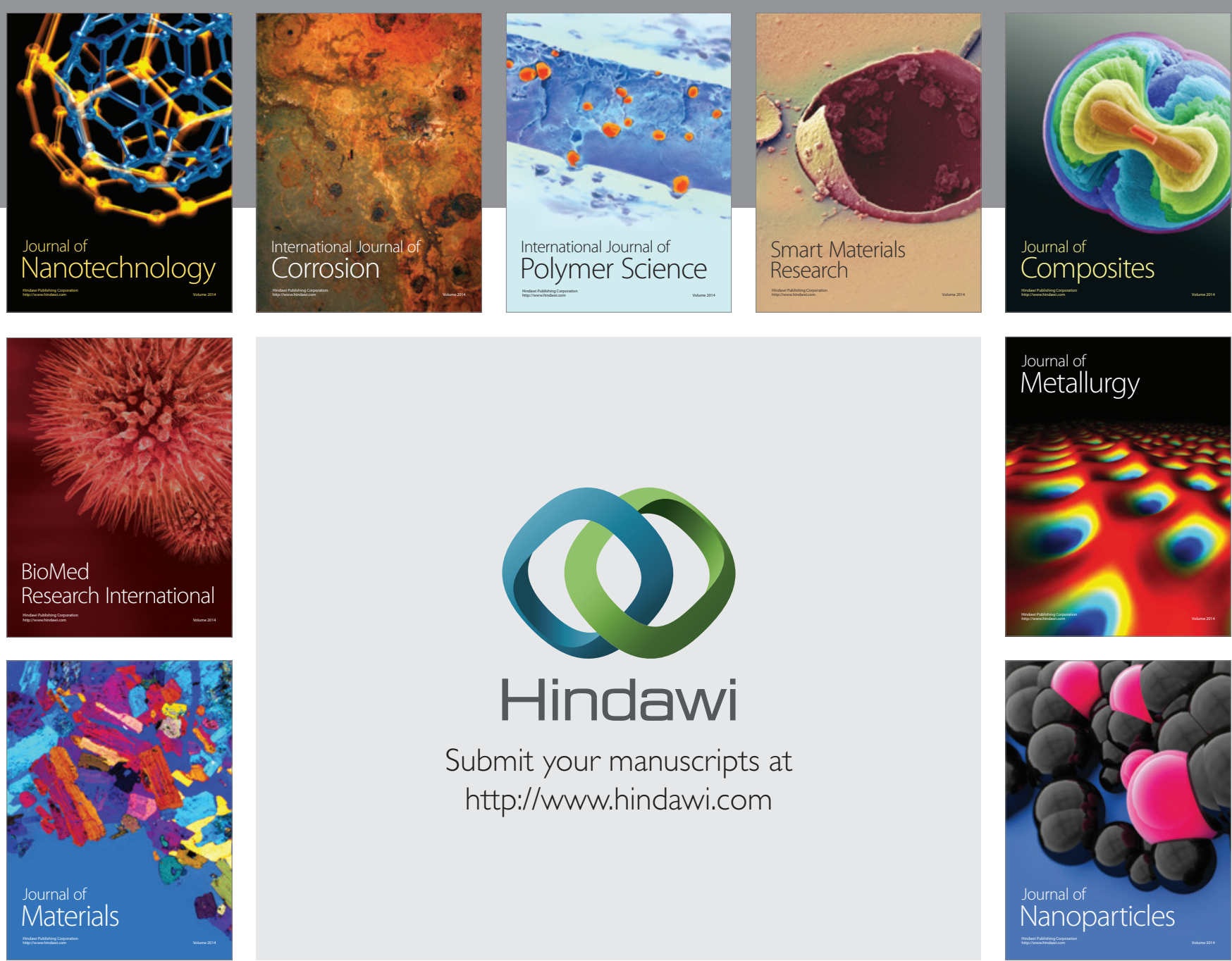

\section{Hindawi}

Submit your manuscripts at

http://www.hindawi.com

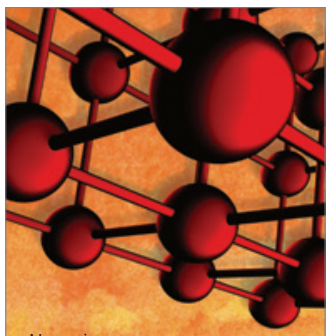

Materials Science and Engineering
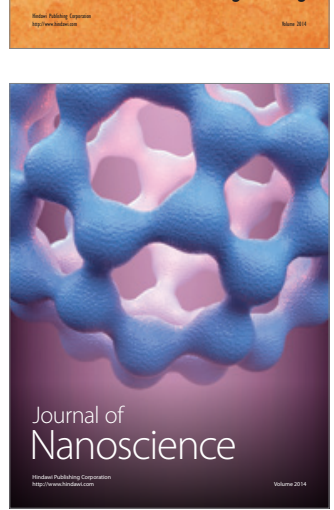
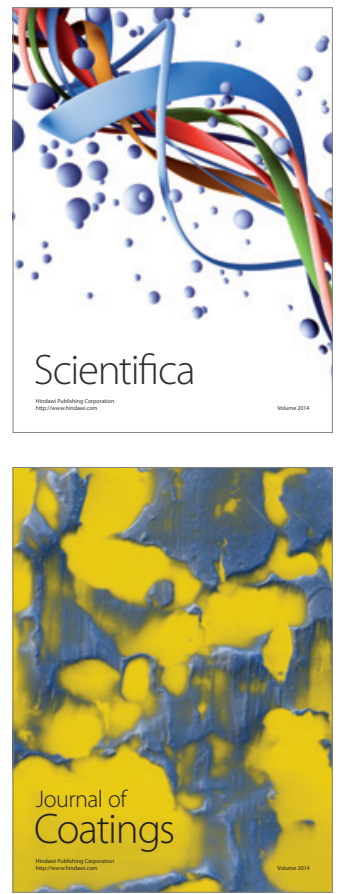
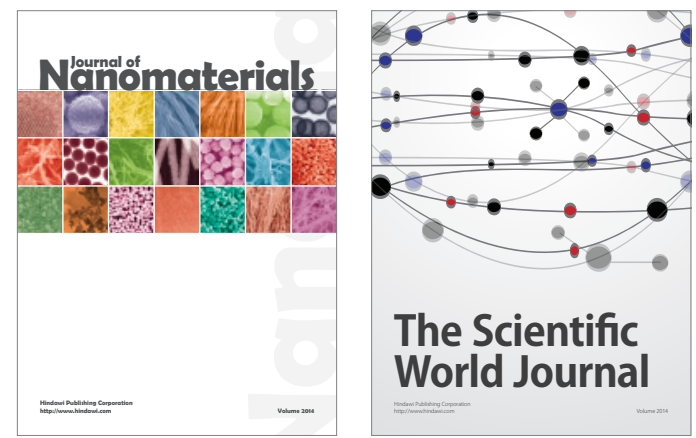

The Scientific World Journal
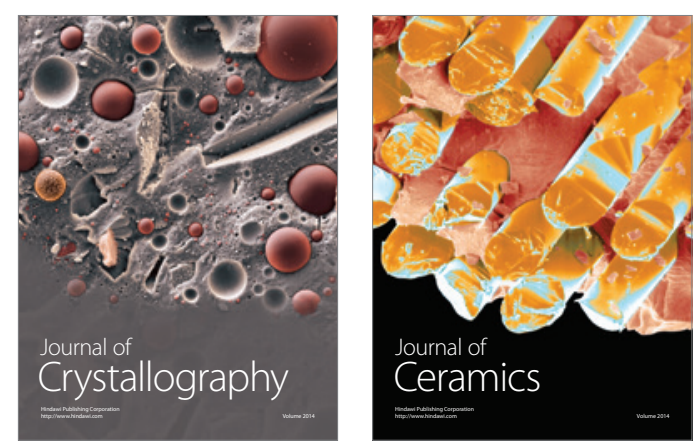
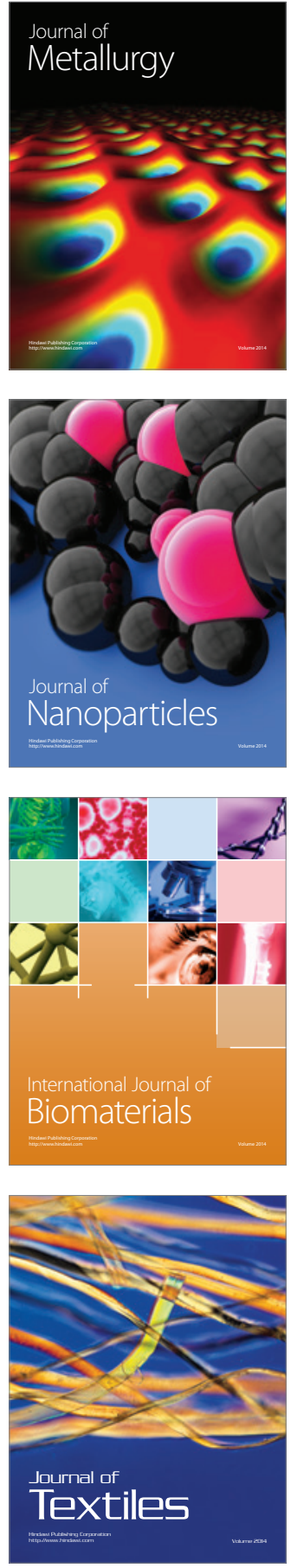